\title{
KINEMATIC-DYNAMIC INTERRELATIONS BETWEEN THE DROP JUMP ON INCLINED PLATFORM AND THE TAKE-OFF IN THE HORIZONTAL ATHLETICS JUMPS
}

\author{
Ognyan Miladinov, Vladimir Velin \\ National Sports Academy „Vassil Levski““
}

\begin{abstract}
The drop jump is a frequently used and widely examined training exercise aimed at the development of one of the most important qualities in sports with speed-strength character-the explosive power. The common options for execution of this exercise suppose the general development of the explosive power of the lower limbs without taking into consideration the kinematics and dynamics related to a certain kind of sport or sports discipline.

The main aim of the research is to reveal reliable interdependencies of kinematic and dynamic parameters of movements between the drop jump on an inclined platform and the take-off from the board in the long jump and the triple jump. The research is aimed at modeling the parameters of execution of this exercise so that it can meet the kinematics and dynamics of the take-off in the horizontal athletics jumps.

We examined some kinematic and dynamic parameters of movements in the drop jump on an inclined platform with different angle of inclination and made a comparison with the same parameters in the take-off in the competitive events long jump and triple jump. We determined significant differences and conformities between the researched parameters. On the base of the conclusions made we designed a piece of training equipment so that this exercise can be implemented in practice.
\end{abstract}

Key words: long jump, triple jump, drop jump, explosive power, inclined platform

\section{INTRODUCTION}

Explosive power is one of the main factors of sports achievement in many kinds of sports (Bachvarov, 1985; Bobbert, 1987; Popov, 1972). The diversity of plyometric means for development of this quality is quite big. One of the most frequently used methods for development of the explosive power is the so called plyometric method, which is a take-off after performing a drop jump (Bachvarov, 1964; Verhoshanskiy, 1964, 1967; Miladinov, 1999). The essence of this exercise is in the use of the energy of the dropping body where in order to perform the subsequent effective take-off one should have an extreme concentration and fulfill three main conditions:

1. Timely pre-activation of the muscles before the eccentric phase.
2. Short and fast eccentric phase.

3. Immediate transition from eccentric to concentric phases.

In practice, the take-off after performing a drop jump is executed in different ways:

- with minimum flexing of the knee joints upon landing on the support, where the takeoff is executed with movements mainly from the ankles;

- with a deep squat upon landing on the support and subsequent take-off with an active involvement of the gluteus and quadriceps (Bobbert, 1990);

- with involvement or without involvement of the arms as swing parts;

- from place or with approach run (Ruan, Li, 2008);

There are different techniques of execut- 
ing the take-off after a drop jump. Walsh $\mathrm{M}$, at al (2003) proved that the manipulation of jump technique played larger role than jump height in the manipulation of important jump parameters. On the one hand, some authors suggest that the drop jump should be executed from the height of $70-110 \mathrm{~cm}$ in order to achieve a maximum effect (Bachvarov, 1964; Verhoshanskiy, 1964; Popov, 1972). On the other hand, other authors (Bobbert, 1987; Peng, 2011) do not recommend execution of the drop jump from heights greater than 40 $-60 \mathrm{~cm}$ due to the low training efficiency or due to the risk of injuries.

Upon the execution of take-off after a drop jump, the landing after the drop of the body is on a horizontal platform and athletes always approach the support with the front part of their foot, while their shin is at an almost right angle $\left(90^{\circ}\right)$ with the support. On the other hand, the take-off in the horizontal athletics jumps is performed with quick roll from heel to toes, and the angle when placing the foot on the support is considerably smaller $\left(65-70^{\circ}\right)$. In this sense, we could say that the classic drop jump is aimed at the development of the general explosive power and not at the particular competitive sports discipline.

\section{METHODS}

The main aim of the research is to reveal reliable interdependencies of kinematic and dynamic parameters of movements between the drop jump on an inclined platform and the take-off in the long jump and the triple jump. This would enable the modeling of the parameters of execution of this exercise so that it can meet the kinematics and dynamics of the take-off in the horizontal athletics jumps.

\section{Tasks}

To examine the kinematic and dynamic parameters of the take-off in the drop jump on an inclined platform.

To make a comparative analysis of the researched parameters between the drop jump on an inclined platform and the take-off from the take-off board in the long jump and the triple jump.

We used the following research methods and equipment:

- video-metrics - digital camcorder Casio with shooting frequency of 240 shots per sec;

- strain-gauging dynamo graphics -Twochannel strain-gauging platform with analogdigital transformer at frequency $1 \mathrm{Khz}$;

- computer programs for kinematic analysis - Dartfish;

- math-statistical research methods -variation analysis.

On the one hand, 10 athletes, practicing jumping disciplines, took part in the research. They made two different attempts in the drop jump on an inclined platform - with two feet and with one foot and with two different inclinations of the platform $-15^{\circ}$ and $25^{\circ}$. We had designed special supports so that the strain-gauging platform had a certain angle of inclination. In this way, when executing a drop jump on an inclined platform, there is an angle between the lower leg and support of about $65^{\circ}$ or $75^{\circ}$. The researched athletes executed the exercise from two different jumping heights - from $30 \mathrm{~cm}$ and from $60 \mathrm{~cm}$. The exercises were performed after a standard warm up. The subjects had not been trained before to perform the exercises as regards the arm movement and body parts positions at the different moments. They were only instructed to execute the jump off the platform as explosively as possible (with a big force and a minimum contact time). 
Thus, each athlete performed 16 jumps.

On the other hand, we shot and analyzed the take-off phase in long jump and triple jump of athletes with different qualifications in competitive environment. The camcorder was steady and placed perpendicularly of the runway, just opposite the take-off board. The total number of jumps shot is 195. Table 1 shows the measured parameters.

Table 1. Measured parameters

\begin{tabular}{lcr}
\hline Measured parameter & Measure units & Illustration \\
\hline Kinematic characteristics of the take-off in horizontal athletics jumps in competitive \\
environment and of the drop jump on an inclined platform
\end{tabular}

The angle of placing (the angle between the 1 shin of the take-off leg and the ground (or platform plane) at the moment of touch-down the Degrees $\left({ }^{\circ}\right)$ support upon take-off.

The angle between the coxofemoral joint, the ankle joint of the take-off leg and the ground (or platform plane) at the moment of touch-down the Degrees $\left(^{\circ}\right)$ support upon take-off.

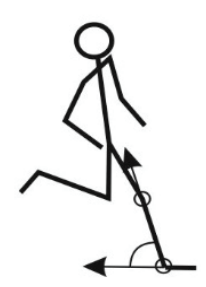

The angle of the push back (the angle between the shin of the take-off leg and the ground (or platform plane) at the moment of the take-off Degrees $\left({ }^{\circ}\right)$ from the support upon the take-off).

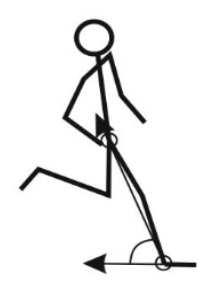

4 The way of placing the foot of the jumping leg upon the take-off.

Kinematic and dynamic characteristics of the drop jump on an inclined platform

5 Value of the first peak of the vertical component of the support reaction.

Kilograms

Fy1

Value of the second peak of the vertical com-

6 ponent of the support reaction.

Kilograms

Fy2

$7 \quad$ Average support reaction.

Kilograms

Fycp.

8 Support time.

Seconds

$\mathrm{T}$

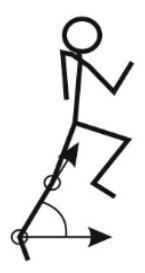




\section{RESULTS AND DISCUSSION}

Table 2 presents the variation analysis of the researched parameters of athletes with different qualification in the long jump and the triple jump in competitive environment. We found out that with all the researched index- es the coefficient of variation (V\%) shows a high and average homogeneity which means that the differences among the athletes along these parameters are insignificant regardless of their qualification.

Table 2. Variation analysis of some kinematic parameters of the movements in the take-off in the horizontal athletics jumps

\begin{tabular}{|c|c|c|c|c|c|c|c|c|c|}
\hline Index & $\mathbf{X}$ & $\pm \mathbf{M x}$ & $\mathbf{S}$ & $\mathbf{E x}$ & As & $\mathbf{R}$ & Min & Max & V\% \\
\hline \multicolumn{10}{|c|}{ Angle of placing of the jumping leg } \\
\hline LJ men & 65.40 & 0.80 & 5.69 & -0.89 & -0.09 & 20 & 55 & 75 & 8.70 \\
\hline LJ women & 65.26 & 0.98 & 6.92 & -0.95 & -0.34 & 22 & 53 & 75 & 10.60 \\
\hline TJ men & 69.58 & 0.75 & 5.33 & -0.99 & 0.23 & 19 & 61 & 80 & 7.67 \\
\hline TJ women & 69.76 & 0.77 & 5.42 & -0.93 & 0.18 & 21 & 59 & 80 & 7.76 \\
\hline \multicolumn{10}{|c|}{ Angle of the push back of the jumping leg } \\
\hline LJ men & 67,90 & 0,98 & 6,91 & $-0,09$ & $-1,06$ & 25 & 54 & 79 & 10,18 \\
\hline LJ women & 69,40 & 1,05 & 7,41 & 0,27 & $-0,41$ & 28 & 54 & 89 & 12,67 \\
\hline TJ men & 63,30 & 0,94 & 6,66 & 0,54 & 0,04 & 27 & 57 & 84 & 16,52 \\
\hline TJ women & 61,92 & 0,92 & 6,50 & 0,87 & 0,79 & 32 & 51 & 83 & 8,49 \\
\hline \multicolumn{10}{|c|}{ Angle of coxofemoral joint - ankle joint - ground upon approach } \\
\hline LJ men & 58.20 & 0.90 & 6.34 & -0.50 & -0.76 & 20 & 45 & 65 & 10.90 \\
\hline LJ women & 59.12 & 1.28 & 9.06 & -1.20 & 0.02 & 30 & 45 & 75 & 15.32 \\
\hline TJ men & 60.90 & 0.73 & 5.18 & -0.27 & 0.06 & 25 & 50 & 75 & 8.51 \\
\hline TJ women & 61.22 & 0.74 & 5.23 & -0.15 & -0.10 & 25 & 50 & 75 & 8.54 \\
\hline
\end{tabular}

The analysis of the researched indexes from the long jump and the triple jump in competitive environment showed the following:

1. The values of the coefficients of asymmetry (As) and Excess (Ex) for almost all measured parameters are less than 1.00. It means that the data distribution is normal and the mean values are credible indicators for analyses.

2. The average value $(X)$ of the angle of placing of the jumping leg in the long jump is the same with men and women and is about $65^{\circ}$; the range of this parameter $(\mathrm{R})$ is within $55-75^{\circ}$. The optimal values of this angle, found in literature, are $65-70^{\circ}$ (Seyfarth, Blickhan and Van Leeuwen, 2000; Popov, 1972; Ivanov, 1977 among others).

The average values $(\mathrm{X})$ of the angle of placing of the jumping leg in the triple jump area is little higher $\left(69^{\circ}\right)$ and this is logical provided that the take-off angle of CM in the triple jump is smaller and the jumping leg is placed for a take-off closer to the projection of CM than it is placed in the long jump. The minimum and maximum values of this angle are also higher than those of the long jump ( $59^{\circ}$ and $80^{\circ}$ respectively). The optimal value of this angle, found in the literature, is $75^{\circ}$ (Popov, 1972; Ivanov, 1977, etc.). 
3. After the variation analysis of the angle of push back at the moment of the take-off from the support upon the take-off, we found out that the mean values of this angle do not differ significantly between men and women - both in the long jump and the triple jump. The mean value of the long jump with the men is $67.9^{\circ}$, and with the women $-69.4^{\circ}$. In the triple jump these values are respectively $63.9^{\circ}$ and $61.9^{\circ}$. What is noteworthy is the fact that the angle of push back in the triple jump is about $10 \%$ smaller $\left(6^{\circ}\right)$ than the one in the long jump. The reason for this is again the smaller take-off angle of CM in the triple jump compared to the one in the long jump $\left(16-17^{\circ}\right.$ against $\left.20-22^{\circ}\right)$. The coefficient of variation of this index shows a satisfactory homogeneity and with all groups it ranges within $\mathrm{V} \%=8.49-16.52$. This means that there are no significant differences between the researched indexes.

4. The angle formed by the coxofemoral joint, the ankle joint of the jumping leg and the horizontal at the moment of the approach of the support is the same in the long jump and the triple jump. The mean values range within only $58^{\circ}-61^{\circ}$. This angle provides information about the position of the coxofemoral joint (respectively of $\mathrm{CM}$ ) in relation to the point of support upon the approach of the jumping leg. It is smaller than the angle of placing of the jumping leg and the reason for this is that the jumping leg isa little flexed at the knee joint upon the take-off.

5. In all researched jumps the foot of the jumping leg approaches the take-off board with the heel, followed by rolling on flat foot and standing on tiptoe. There was no competitive jump where the foot of the jumping leg approached the support with its front part.

The variation analysis of the drop jump on an inclined platform showed that in all variations of its execution regarding the inclination and the height (the drop of the jump respectively) there were no significant differences among the athletes, which is confirmed by the extremely low values of the coefficient of variation (V). Table 3 presents the mean values of the researched parameters in the different variation of execution of this exercise.

Table 3. Mean values of kinematic parameters of the drop jump on an inclined platform (degrees)

\begin{tabular}{cccccc}
\hline $\begin{array}{c}\text { Taking - off } \\
\text { with... }\end{array}$ & $\begin{array}{c}\text { Inclination of } \\
\text { the } \\
\text { platform }\end{array}$ & $\begin{array}{c}\text { Drop of the } \\
\text { jump } \\
\text { (cm) }\end{array}$ & $\begin{array}{c}\text { Angle of } \\
\text { placing }\end{array}$ & $\begin{array}{c}\text { Angle of } \\
\text { coxofemoral joint } \\
\text { ankle joint }- \\
\text { platform plane }\end{array}$ & $\begin{array}{c}\text { Angle of push } \\
\text { back }\end{array}$ \\
\hline one leg & 15 & 30 & 86 & 75 & 78 \\
one leg & 15 & 60 & 86 & 77 & 71 \\
one leg & 25 & 30 & 80 & 70 & 76 \\
one leg & 25 & 60 & 83 & 71 & 77 \\
two legs & 15 & 30 & 90 & 74 & 75 \\
two legs & 15 & 60 & 91 & 75 & 74 \\
two legs & 25 & 30 & 86 & 67 & 71 \\
two legs & 25 & 60 & 86 & 69 & \\
\hline
\end{tabular}


The analysis of the data shows the following:

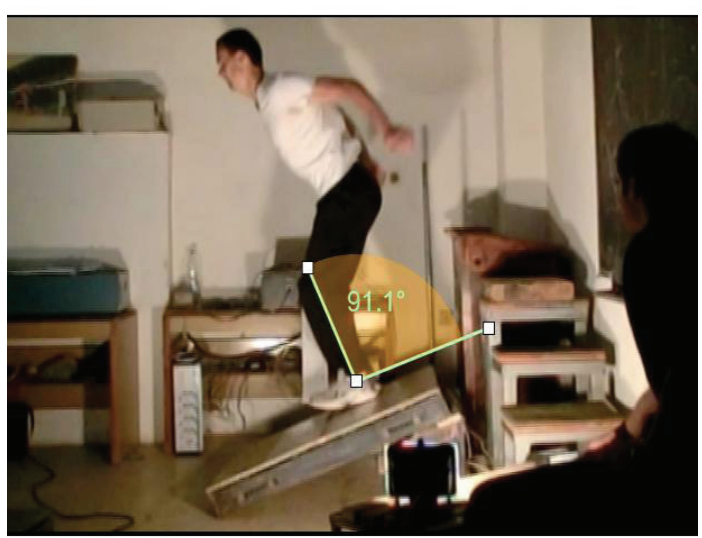

Figure 1. Illustration of the ,, angle of placing”in the drop jump on an inclined platform

1. The angle of placing, i.e. the angle which the lower leg forms with the support upon approach (fig. 1) in the different variations of execution of the drop jump on an inclined platform is bigger than the one in the competitive exercise and averages $83^{\circ}-91^{\circ}$. The analysis showed that the reason for these differences is the greater flexing of the knee joint of the support leg upon the execution of this exercise. That is why, the execution with as little flexing of the knee joints as possible can be used as a methodological guideline upon execution of the exercise. This will make the angle of plac- ing (landing) after the drop jump smaller and closer to the competitive jumps. On the other hand, the measured angle of the coxofemoral joint - ankle joint - platform plane (fig. 2) showed significantly smaller differences with the same angle in the competitive jumps (average $69^{\circ}-70^{\circ}$ ) at the inclination of the platform is $25^{\circ}$.

On the base of the change in the angle of the landing platform after the drop jump and the coach's guidelines, we can completely model the way each athlete places the foot for the take-off.

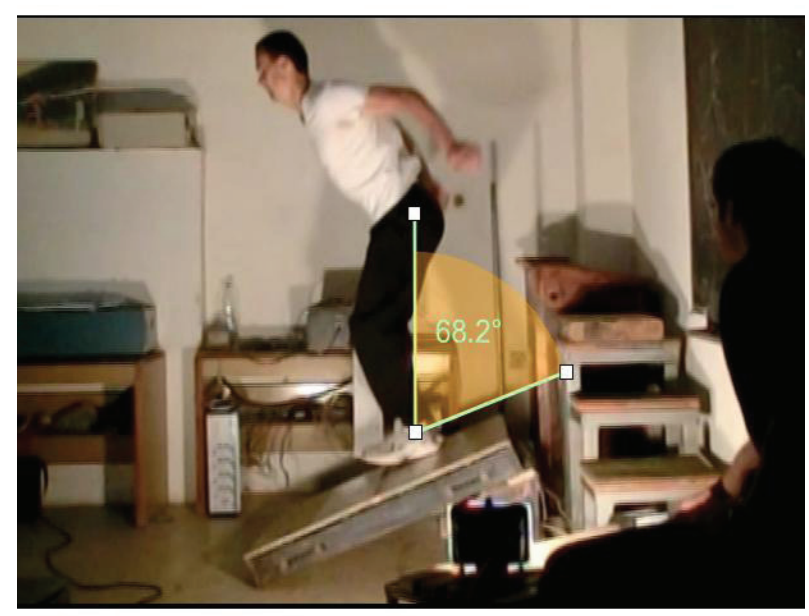

Figure 2. Illustration of the angle "coxofemoral joint-ankle joint-platform plane" in the drop jump on an inclined platform 
2. The angle of the push back, i.e. the angle (fig. 3) is $76^{\circ}$. This shows certain relevance which the shin of the support leg forms with between the exercise and the take-off in the the platform at the moment of the take-off horizontal athletics jumps.

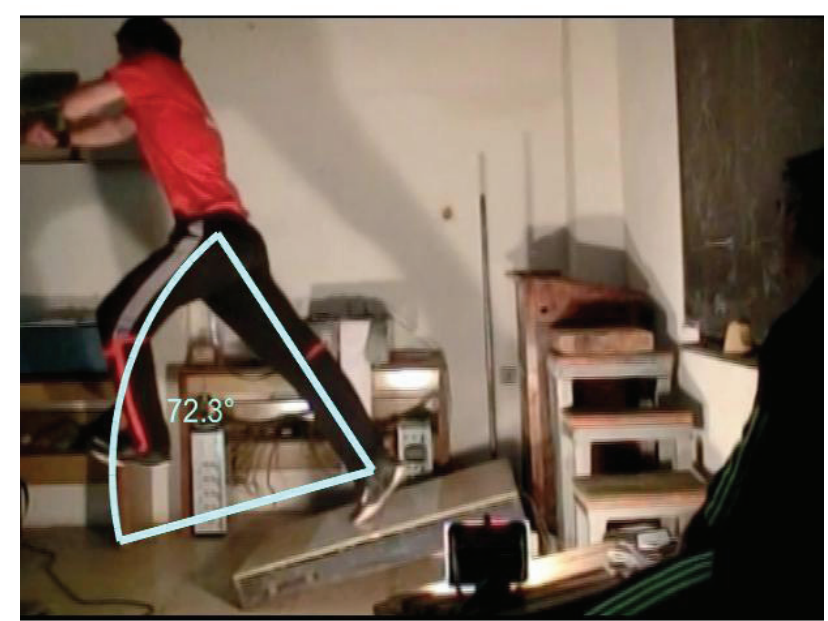

Figure 3. Illustration of the "angle of push back" in the drop jump on an inclined platform

The comparative analysis of the researched kinematic parameters of the movements in the take-off in the horizontal athletics jumps and in the drop jump on an inclined platform showed certain possibilities for bringing the values of these parameters clos- er together. This made us look for a way to model the inclination of the take-off platform so that upon the execution of the exercise these parameters will be as similar as possible to the parameters of the take-off in the competitive jumps.

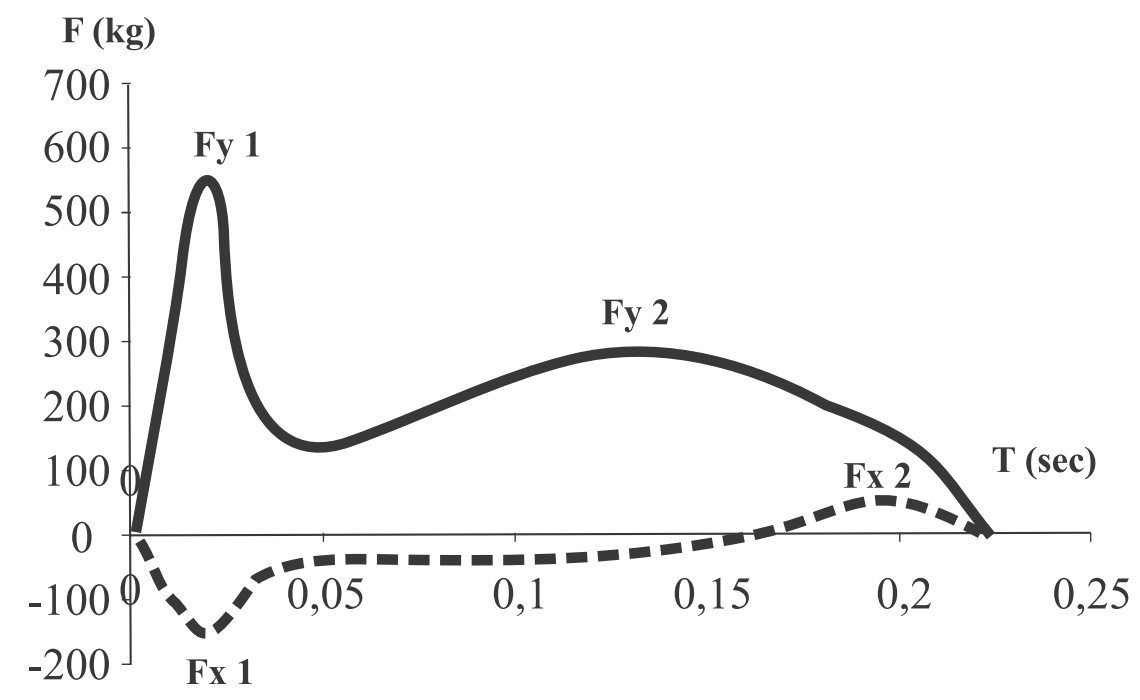

Vertical components

- - Horizontal components

Figure 4. Horizontal and vertical components of the support reaction in the drop jump on an inclined platform 
The analysis of the dynamic characteristics of the movements in the drop jump on an inclined platform showed the following:

1. The graph of the vertical and horizontal components of the support reaction is displayed on figure 4 and shows that the shape of the support reaction is quite identical with the one in the take-off in the long jump and the triple jump. As a hole, the support time $(0.17-0.22 \mathrm{sec})$ is a little more than the one in the competitive jumps $(0.11-0.14 \mathrm{sec})$, but we have to note that the body speed in our exercises is significantly lower and the main goal of their execution is to decrease the support time and increase the applied force.

2. With all measured heights and angles of the platform (table 4) the horizontal component has maximum values of $120-150 \mathrm{~kg}$ in its negative part $\left(\mathrm{F}_{\mathrm{x} 1}\right)$ and of $40-50 \mathrm{~kg}$ in its positive part $\left(\mathrm{F}_{\mathrm{x} 2}\right)$. This is indicative of the high degree of conformity of the interaction with the support with the same index in the take-off in the competitive jumps. For comparison, when executing a drop jump on an inclined surface, the horizontal component of the support reaction is practically missing.

Table 4. Mean values of the dynamic parameters in drop jump on an inclined platform

\begin{tabular}{cccccccc}
\hline $\begin{array}{c}\text { Taking-off } \\
\text { with ... }\end{array}$ & $\begin{array}{c}\text { Inclination of } \\
\text { the } \\
\text { platform } \\
\text { (degrees) }\end{array}$ & $\begin{array}{c}\text { Height of the } \\
\text { drop jump } \\
\text { (cm) }\end{array}$ & $\begin{array}{c}\text { Fy1 } \\
\mathbf{( k g )}\end{array}$ & $\begin{array}{c}\text { Fy2 } \\
(\mathbf{k g})\end{array}$ & $\begin{array}{c}\mathbf{F x 1} \\
\mathbf{( k g )}\end{array}$ & $\begin{array}{c}\mathbf{F x 2} \\
\mathbf{( k g})\end{array}$ & $\begin{array}{c}\text { T support } \\
\text { (sec) }\end{array}$ \\
\hline one leg & 15 & 30 & 550 & 287 & -125 & 40 & 0.223 \\
one leg & 15 & 60 & 899 & 315 & -150 & 47 & 0.212 \\
one leg & 25 & 30 & 585 & 281 & -134 & 32 & 0.211 \\
one leg & 25 & 60 & 846 & 314 & -150 & 47 & 0.209 \\
two legs & 15 & 30 & 837 & 367 & -134 & 45 & 0.188 \\
two legs & 15 & 60 & 985 & 405 & -146 & 47 & 0.176 \\
two legs & 25 & 30 & 858 & 365 & -125 & 42 & 0.171 \\
two legs & 25 & 60 & 961 & 378 & -79 & 43 & 0.182 \\
\hline
\end{tabular}

3. The vertical component of the support reaction is also close, in the nature of its change, to the one in the take-off in the long jump and the triple jump. It does not differ significantly from the execution of the drop jump on a horizontal surface. The differences in the three cases are only in the values of the measured force. This fact called for examination of the influence of the change in the inclination of the platform and the height (the drop) of the jump on the magnitude of the support reaction.
The increase of the height of the drop jump from $30 \mathrm{~cm}$ to $60 \mathrm{~cm}$ with both inclinations of the platform leads to an increase in the forcepeak (Fy1) from 585 to $900 \mathrm{~kg}$ (fig. 5 ). The magnitude of the second peak (Fy2) in many cases is higher than the magnitude in the long jump and the triple jump. The magnitude of the second peak (Fy2) also increases with the increase of the height (drop) of the jump, even though in a lower extent, and this is directly related to the manifestation of active muscle efforts. 
On the other hand, the increase of the inclination of the platform at the same height of the jump leads to a decrease in the force of

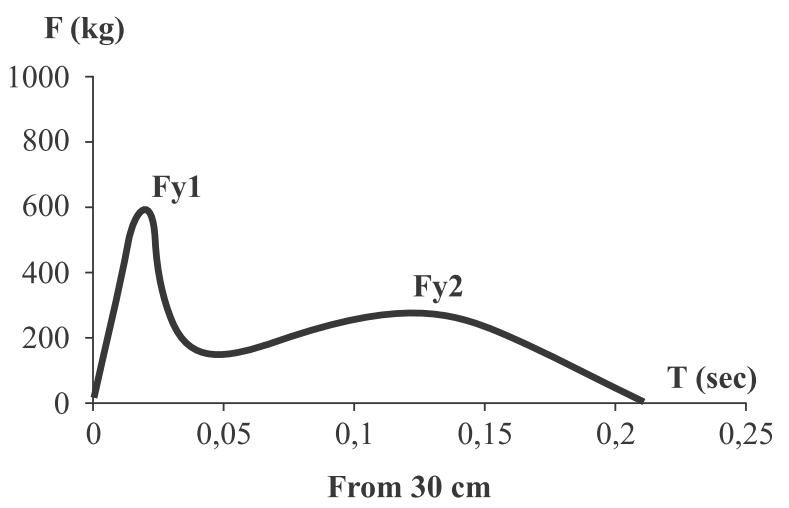

both the first and the second peak of the vertical component of the support reaction.

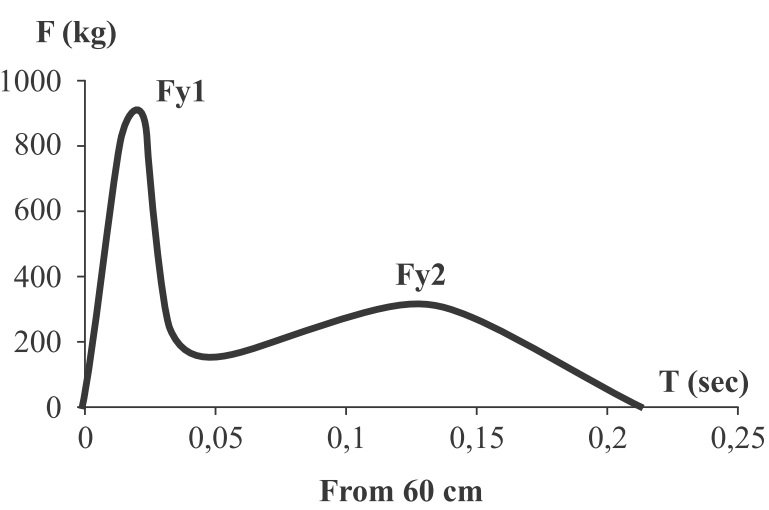

Figure 5. The vertical component of the support reaction in the drop jump on an inclined platform from the height of 30 and $60 \mathrm{~cm}$.

4. As regards the support time, we found out that the change of the degree of the inclination of the platform and the height of the jump does not lead to significant changes in the jump. In all cases, the support time does not change with more than $0.011-0.013 \mathrm{sec}$. Its mean value in all variations of execution ranges from 0,223 and 0,209 sec. Taking into consideration the not so high speed of the movement of the body upon the drop on the support (about $3.5 \mathrm{~m} / \mathrm{sec}$ in a jump from $60 \mathrm{~cm}$ height), this support time is normal for an athlete with good preparation and is indicative of the efficiency of the execution of this exercise. We should point out that a significant part of the researched individuals showed support time of $0.135-0.150 \mathrm{sec}$, which is quite identical with the support time in the take-off in the long jump and the triple jump in competitive environment. At one and the same time, the displayed greater support reaction means a higher impulse of the force which leads to a more efficient execution.

5. We fell short of our expectations that all of the athletes would approach the support with the heel. Most probably, during the first executions of jumps on an inclined surface, some preliminarily formed habit is displayed and that is why part of the researched athletes approached the support with the front part of their foot (fig. 6). This, to some extent, is the reason for the increase in the support time.
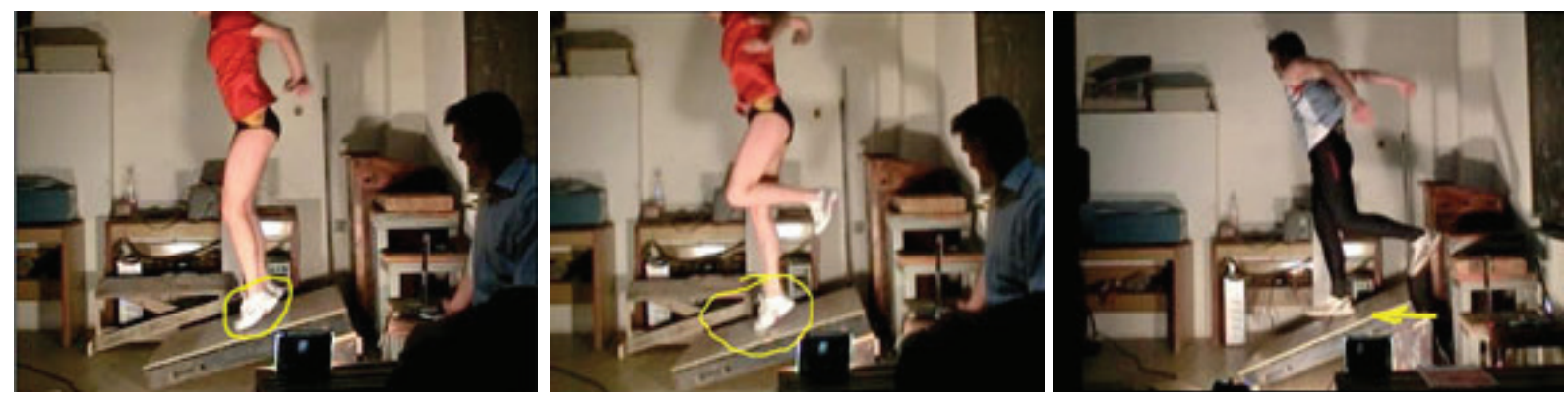

Figure 6. Illustration of approaching the support in the drop jump on an inclined platform 
The increase in the angle of the inclination of the platform normally led to the increase in the number of the cases when the athletes approached the platform with their heel first $-60 \%$ at an inclination of $15^{\circ}$ and about $90 \%$ at an inclination of $25^{\circ}$. The approach with the heel can also be used as a methodological guideline in the drop jump on an inclined platform.

\section{CONCLUSIONS}

1. The take-off after a drop jump on an inclined surface with an angle $15^{\circ}-25^{\circ}$ models to a great extent the kinematics and dynamics of the take-off from the take-off board in the competitive horizontal athletics jumps. Therefore, this exercise could be an efficient means for development of the explosive power of the lower limbs in a regime, close to the

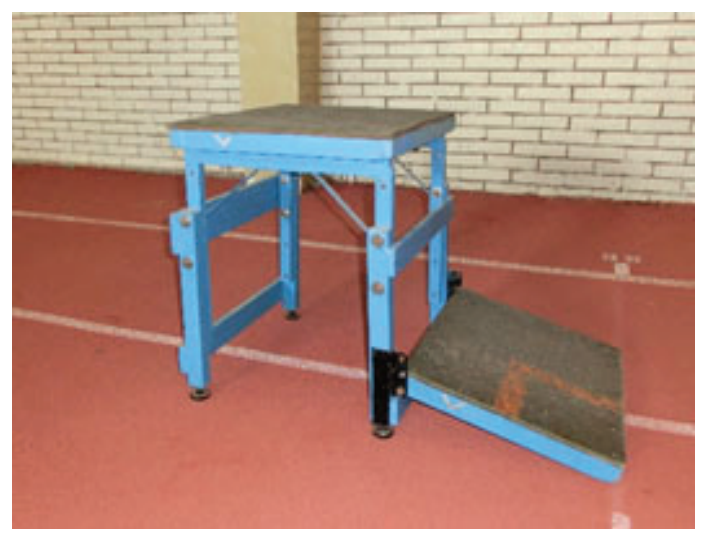

Figure 7. Training equipment for drop jump on an inclined platform

\section{REFERENCES}

Bachvarov M, Hristov G, Georgiev G, Tsvetkov Ts. (1972). Metod za razvitie na spetsialna vzrivna sila pri skoka na daljina, $\mathrm{Va}$ prosi na fizicheskata kultura, Vol. 3, p. 145.

Bachvarov M., Bachvarov D. (1985). Kontrol I optimizirane na podgotovkata $\mathrm{v}$ skoka na daljina chrez spetsializirano raznoobrazie, Vaprosi na fizicheskata kultura, Vol. 7, p. 12.

Bobbert MF., Huijing PA., van Ingen take-off in the long jump and the triple jump.

2. The development of different variances for execution of the drop jump on an inclined platform, as well as methods for its implementation in the training process could lead to perfection of the methods for development of the explosive power in the horizontal athletics jumps.

3. The building of a piece of training equipment for a drop jump on an inclined platform does not take much time and effort and is inexpensive, which means that it would not be difficult to implement similar methods in practice. As a result of our analyses and the conclusions we outlined, we designed and built two types of pieces of training equipment for execution of drop jump on an inclined platform in training conditions (Fig. 7).

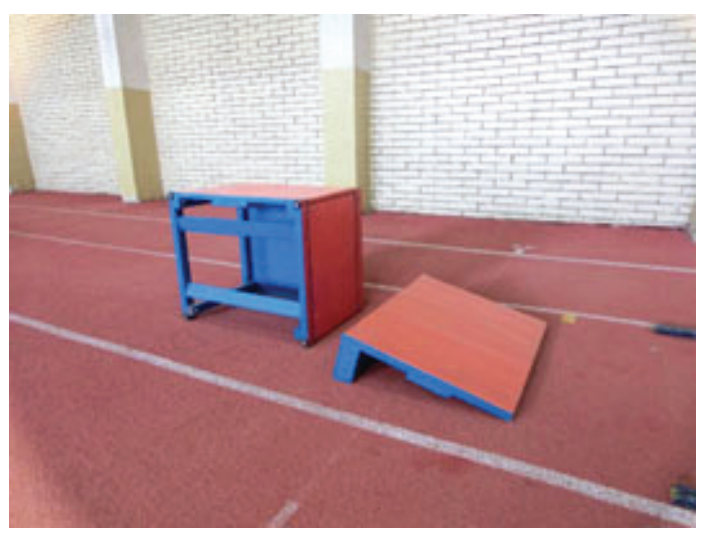

Schenau GJ. (1987). Drop jumping. I. The influence of jumping technique on the biomechanics of jumping, Med Sci Sports Exerc. Aug;19(4) 332-8.

Bobbert MF., Huijing PA, van Ingen Schenau GJ. (1987). Drop jumping. II. The influence of dropping height on the biomechanics of drop jumping. Med Sci Sports Exerc. Aug; 19 (4):339-46.

Ivanov I. (1977). Skok na daljina, Sofia.

Popop V. (1972 ). Prijok v dlinu, Moskva. 
Bobbert MF. (1990). Drop jumping as a training method for jumping ability, Sports Med, January; 9 (1): 7-22.

Marshall BM., Moran KA., (2013). Which drop jump technique is most effective at enhancing countermovement jump ability, "countermovement" drop jump or "bounce" drop jump? J Sports Sci.; 31(12):1368-74. DOI: 10.1080/02640414.2013.789921. Epub 2013 Apr 30.

Miladinov, OM. (1999). Dinamicheski osobenosti na niakoi skokovi uprajneniya pri skachachi na daljina, Sport I nauka, Vol. 4-5.

Miladinov, OM. (2006). New aspects in perfecting the long jump technique, New studies in athletics, Vol. 4.

Peng HT., Kernozek TW., Song CY. (2011). Quadricep and hamstring activation during drop jumps with changes in drop height, Phys Ther Sport. August; 12(3):12732. DOI: 10.1016/j.ptsp.2010.10.001. Epub 2010 Nov 26.

Peng, HT. (2011). Changes in biomechanical properties during drop jumps of incremental height. J Strength Cond Res. Sep- tember; 25(9): 2510-8.

Ruan M, Li L. (2008). Influence of a horizontal approach on the mechanical output during drop jumps, Res $Q$ Exerc Sport. March; 79 (1):1-9.

Seyfarth A., Blickhan R. and Van Leeuwen J. (2000). Optimum take-off techniques and muscle design for long jump. J Exp. Biol 203 (4), $741-750$.

Toupa VV., Aleshenski SH., Ter-Ovansian IA (1980). Biomehanicheskie aspekti tehniki prijka v dlinu.

Verhoshanskiy, YV. (1964). Novoe v silovoi podgotovke pri gunov, Liohkaya atletika, Vol. 7, p. 22.

Verhoshanskiy, YV. (1967). Polezni li prijki v glubinu?, Liohkaya atletika, Vol. 12, p. 9.

Walsh M., Arampatzis A., Schade F, Brüggemann GP. (2003). The effect of drop jump starting height and contact time on power, work performed, and moment of force. Journal of Strength and Conditioning Research. 18(3). 561-566.

\section{Corresponding author:}

Ognyan Miladinov

Track and field athletics department National Sports Academy „Vassil Levski“ Studentski grad, 21, Acad. Stefan Mladenov str.

Sofia 1700, Bulgaria E-mail:ogimil63@gmail.com 